\title{
الأسس الثقافية في تعليم اللغة العربية
}

\section{بمدرسة "إسماريا القرآنية" المتوسطة الإسلامية بندار لامبونج}

\section{Rima Ajeng Rahmawati}

e-mail: nurulfadhilah172@gmail.com

UIN Raden Intan Lampung

Jln.Endro Suratmin Sukarame Bandar Lampung

ملخص :هناك الأسس لتعليم اللغة العربية لغير الناطقين هما، من إحدى أسس لتعليم اللغة الثانية هي الأسس الثقافية التي لها أهمية كبيرة لتقليل

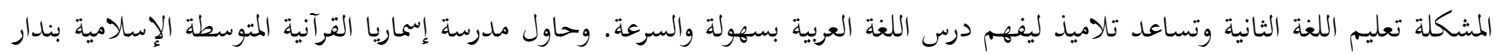

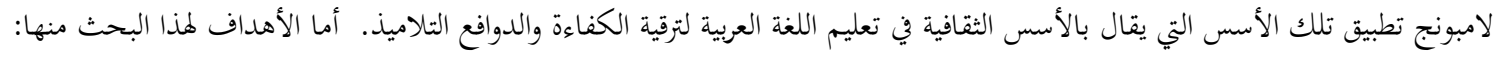

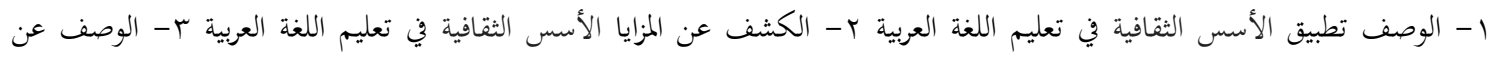

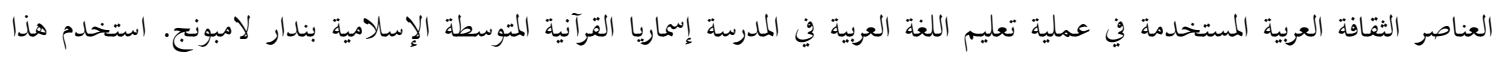

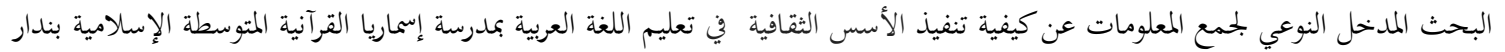

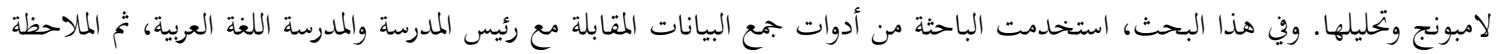

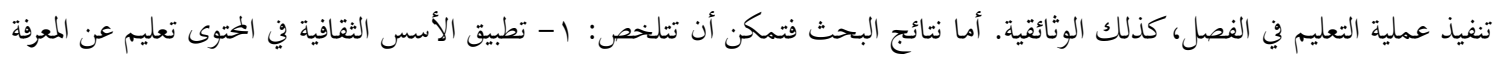

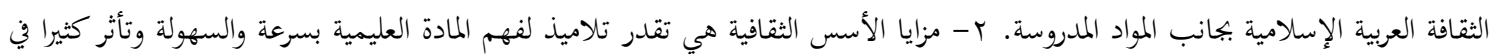
ترقية الكفاءة والدوافع التلاميذ في تعليم اللغة العربية بـ- بعض العناصر الثقافة العربية الإسلامية المستخدمة في تعليم اللغة العربية منها:

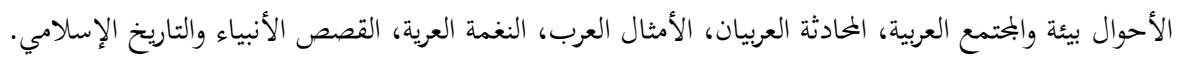

الكلمات الأساسية: الأسس الثقافية، تعليم اللغة العربية

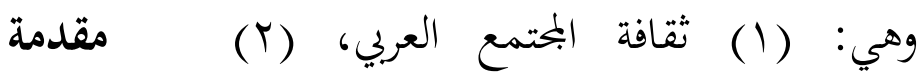

كان تعليم اللغة المدروسة التي

يستوعبها الدارسون لما صورتا المتميزة، وهي لا تعني صورة اللغة الأولى ولا هي اللغة الثانية. فيجري تعليم اللغة العربية في المدارس

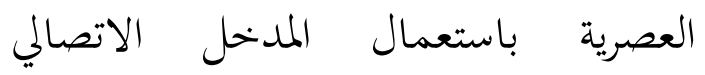
وبالطريقة الحديثة. فهذا المنهج يهدف إلى أمور تبنى على مصادر الأهداف في تعليم اللغة العربية التي تتكون من أربعة عوامل
التطورات العلمية والفنية والحضارة بمعناها

الواسع، (ب) خصائص نمو التلاميذ، (ع) (1) طبيعة المادة الدراسية.'

كما كتبا محمد فرج أبوتبينة و ميلاد

محمد المبروك حضيري في مقالتهما تحت العنوان "كفايات معلم اللغة العربية

$$
\begin{aligned}
& \text { 'إسماعيل زكريا، طرق تلدريس اللغة العربية، }
\end{aligned}
$$

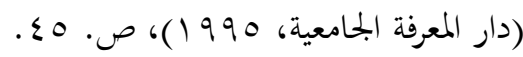


للناطقين بغيرها وفق معايير الجودة والإتقان"، هنك مشكلة الدراسة تنحصر في برنامج تعليم اللغة العربية للناطقين بغيرها وبحث طرق تطوير هو كذلك قلة الإهتمام بالثقافة العربية الإسلامية للوصول للكفاية الثقافية وعدم وجود برنامج حديث يواكب التقديم العلمي التكنولوجي كمشكلة الازدواجية اللغوية بينما يتعلمه الدارسون داخل حجرات الدراسة وبينما يواجهونه في البمتمع خارجها من لغات مختلفة وتداخل مستويات اللغة الأم الصوتية بالمستويات الصوتية للغة المدف.

يرى جون شومان أن الأسس الثقافية للغة المستهدفة في عملية تعلم اللغة الأجنبية سوف يقلل المشكلة في تعلم واكتساب اللغة الثانية. فلذلك، يجب أن تدرج المعلومات والسجالت من الثقافة العربية لأها مهمة جدا في فهم النصوص r محمد فرج أبوتبينة و ميلاد محمد المبروك حضيري، كفايات معلم اللغة العربية للناطقين بغيرها

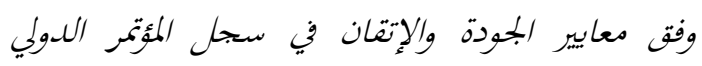
الثاني، (مالانج: Aditya Media Publishing
اللغة العربية. وليس من الخطأ إذا كان الرسوم التوضيحية في ثقافة اللغة المستهدفة مستخدمة في تعلم اللغة ليساعد تسريع عملية تعلم اللغة المستهدفة. ومن المدارس التي تهتم كثيرا على لى تعليم اللغة العربية وكذلك الأسس الثقافية في تعليم الغة العربية هي المدرسة الإسماريا القرآنية المتوسطة بندار لمبونج، تستخدم هذه النظرية لمساعدة على ترقية دوافع الطلاب خصوصا في التعليم اللغة العربية. بعد أن لاحظت الباحثة ما وقع في الميدان ترى، أولا أن المدرسة اللغة العربية تستخدم

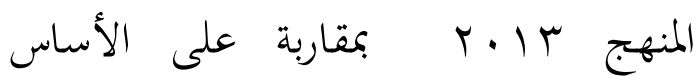
الثقافة العربية الإسلامية أثناء التعليم، ثانيا أن هذا الملدرسة تهم كثيرا على التحسين والتحفيظ القرآن الكريم ولكن أكثر من التلاميذ متخرجين من الإبتدائية الحلكومية مهم كانت لم يعرفون كثيرا عن الأحروف الحجائية واللغة العربية. أ- مفهوم الثقافة

$$
.011 .06(Y \cdot 1 \varepsilon
$$


وفقا لإدوارد ب. تايلور بتعريف

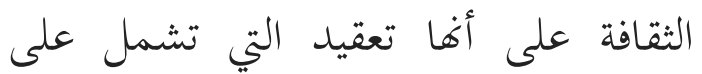

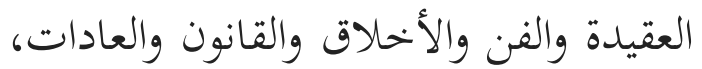
وتم الحصول على جميع أشكال الحياة من ونس ولن

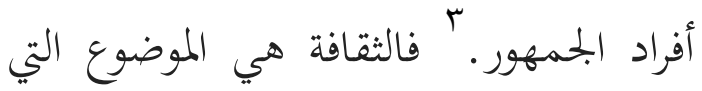
يحملها البحتمع، فهي دلالة على خصائصه الجوهرية وإمكاناته المادية والمعنوية، بل هو رمز على دلالته الحضارية التي تعبر عن شخصيته العامة، بما تنطوي عليه من أفكار

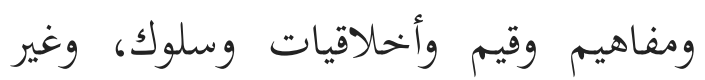
ذلك.

وتحتل الثقافة باعتبارها طرائق حياة الشعوب وأنظمتها السياسية الإقتصادية والإجتماعية والتربوية مكانة هامة في تعليم وتعلم اللغات الأجنبية، وهي تعتبر مكونا
أساسيا مكملا مهما لمحتوى المواد التعليمية في هذا الميدان.

إن اللغة كما نعلم وعاء الثقافة، واللغة العربية دون غيرها من اللغات ترتبط بثقافة الناطقين بها بصفة خاصة، وبثقافة الشعوب الإسلامية بصفة عامة ارتباطا

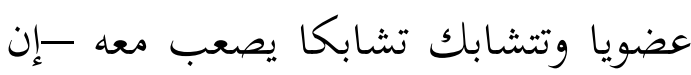

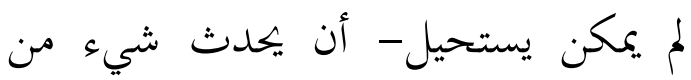

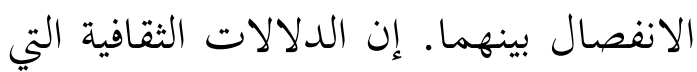
تحملها عناصر اللغة العربية تتعدى بجرد

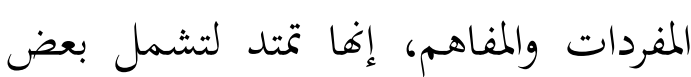
جوانب البنية اللغوية ذاها. من هنا وجب أن تخظي الثقافة العربية بمزيد من الاهتمام يتكافأ مع أهمينها http://iindramawan.blogspot.co.id/2013/03/upay a-melestarikan-budaya-bangsa.html " محمد محمود الخوالدة، أساس بناء المناهج

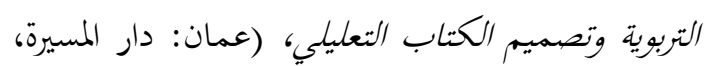

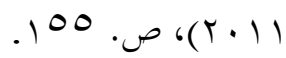

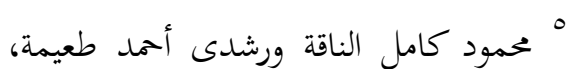

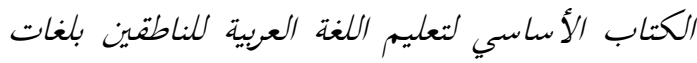

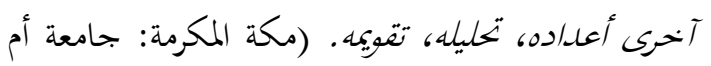
القرى، ז99 (19)، ص. • •ـ 
ودورها بالنسبة للغة العربية بل ضرورتها لفهمها واستعابها لدلالات الألفاظ فيها.
هناك بحموعة من الأساس بتعل من الثقافة جزء أساسيا من تعلم اللغة الأجنبية

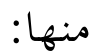

ج- الثقافة أساس لتعليم اللغة العربية

\section{لغير الناطقين بها}

وهناك الأسس لتعليم اللغة العربية

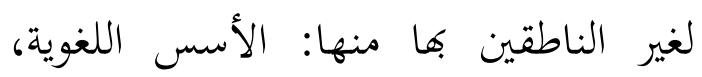

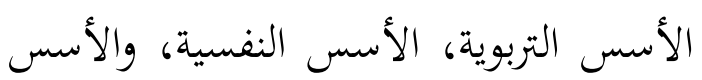

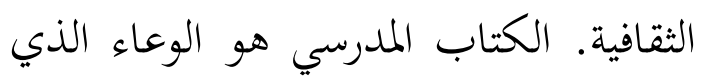

يحمل الثقافة فهو يكتب بالرموز التي تكون

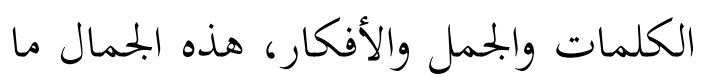

هي في حقيقتها إلاّ تعبير عن الثقافة.

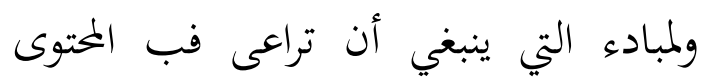

الثقافي للمادة التعليمية الأساسية لتعليم اللغة العربية لغير الناطقين بها.

رشدي أحمد طعيمة، أساس المعتمية

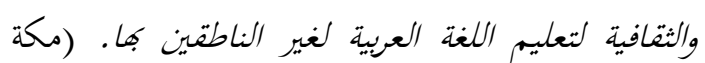

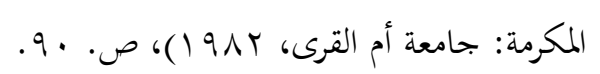

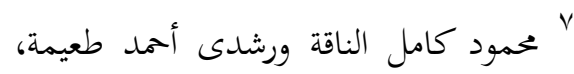

الكتاب الأساسي لتعليم اللغة العربية للناطقين بلغات التهات

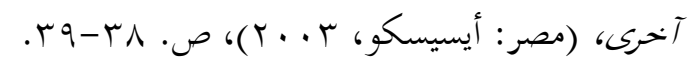

أ) أن القدرة على

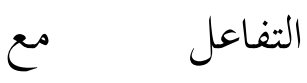

الناطقين باللغة لا

تعتمد فقط على

اتقان مهارات

اللغة، بل تعتمد

أيضا على ثقافة

أهل اللغة وعاداتما

وآمالها وتطلعاها.

ب) أن فهم ثقافة اللغة الأجنبية

والتفاعل معها أمر مهم في

حد ذاته، فالتفاهم العالمي

أصبح الآن الأهداف

الأساسية للتعليم في أي بلد

$$
\text { من بلدان العالم. }
$$

ج) أن الدارسين أنفسهم عادة بلدمان

يكونون مشغوفين بالناس

الذين يتكلمون اللغة التي 
يتعلمونا، ويودون معرفة

أشياء مثيرة عنهم.

د) أن العادت الثقافية تشبه إلى

حد كبير المهارات اللغوية،

فالمتحدث باللغة يتصرف

بشكل وبطينة

تلقائية، كما أنه يتحدث

اللغة بنغس الطريقة، ومن

ثم ينبغي أن تعامل الثقافة

كما تعامل مهارات اللغة

في المواد التعليمية.

ه) أن الكثير من الكتابات

والدراسات في ميدان تعليم

اللغة الأجنبية تكاد بتمع

على أن الثقافة هي الهدف

النهائي من أي مقرر لتعليم

$$
\text { لغة أجنبية. }
$$

و) أن الثقافة ابعاد ماضية

وحاضرة ومستقبلة، ومن ثم

لا تقتصر المادة التعليمية

على تقليم بعد واحد منها،

وإنما بيجب تقديم لحاضر
الثقافة ثم ماضيها ثم آمالما

وتطلعتها وسعيها نخو تحقيق

مستقبل أفضل.

ز) أن ل ل عموميات

$$
\text { وخصوصيات وشواذ. }
$$

ح) أن للدارسين أغراضا متعددة

من دراسة اللغة والثقافة.

منها الغرض الديني، والغرض

السياسي، والغرض التجاري

والوطيفي والعلمي وغير

ذلك.

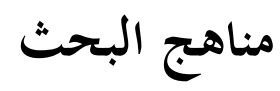

استخدمت الباحثة المدخل الكيفي

لجمع المعلومات وتحليلها. وبالنظر إلى موقع البحث فيكون البحث الميدان لأن هذا

البحث يعتمد على البيانات البمموعة من

الواقع مباشرة يهدف إلى تصوير ورسم

الواقع التي توجد في الميدان. ومنهج هذا

البحث هو المنهج البحث الوصفي على

النوع التحليلي. 
أما مصادر البيانات في هذا البحث

فهي العملية التعليمية، مدرسة اللغة العربية، التلاميذ، المنهج الدراسي والخطط التعليمية.

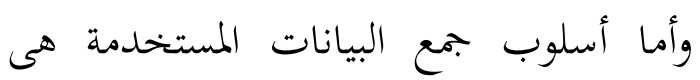
الملاحظة المشاركة، والمقابلة العميقة، والطريقة

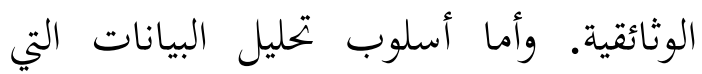
استخدمها الباحث باستخدام نموذج التفاعلي ميليس وهوبرمان وهي جمع البيانات وتخنفيضها

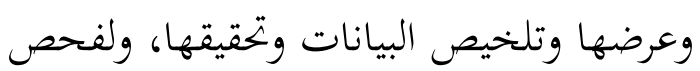

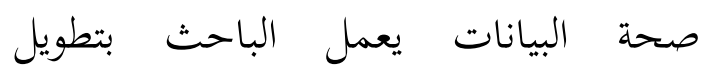
الإشتراك، وعمق الملاحظة، والتثليث.

\section{نتائج البحث ومناقشتها}

في هذا المبحث ستعرض الباحثة

البيانات عن نتائج البحث ما يتعلق بتطبيق الأسس الثقافية في تعليم اللغة العربية بمدرسة إسماريا القرآنية المتوسطة الإسلامية

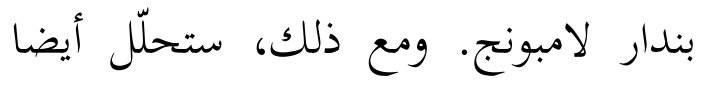
الباحثة المحاولات أو الجهود التي تقوم بها مدرسة إسماريا القرآنية التي تتضمن على الأسس الثقافية من حيث الطريقة تطبيقها، مزايا من تطبيقها وك> لك العناصر الثقافة العربية الإسلامية المستخدمة في تعليم اللغة

العربية بمدرسة إسماريا القرآنية المتوسطة الإسلامية بندار لامبونج.

\section{() تطبيق الأسس الثقافية في تعليم} اللغة العربية بمدرسة إسماريا

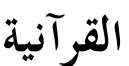

أن نظرية الأسس الثقافية ل"جون

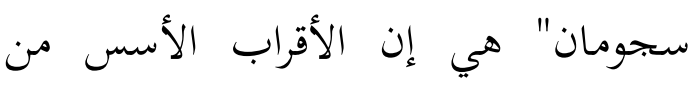
العناصر الإجتماعية والثقافية في تعليم اللغة الثانية فستكون تعليم اكثر الفعالية والجذابية في إبجاح تعليمه. الفرق بين الخطوة تطبيق

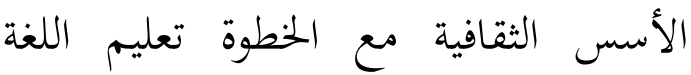
العادية هي في ادخال العناصر الثقافة العربية أثناء تنفيذ تعليم اللغة العربية وتظهر المدرّسة تلاميذها عن الفروق بين الأحوال والأمثال، البيئة والمحتمع العربية مع الأحوال والأمثال، البيئة والمتمع إندونيسيا. استخدام هذه الطريقة ليست في طول الوقت تعليمها، على أكثر استخدمت

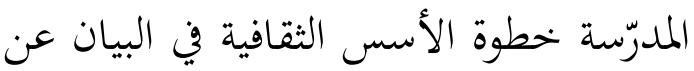

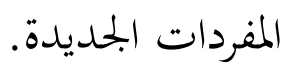


بناء على نتيجة تحليل البيانات

إحصائي، أن تعليم اللغة العربية بتطبيق نظرية الأسس الثقافية له علاقة قوية بنتيجة هذه المادة ويساعد لتحقيق الهدف من الأهداف تعليم اللغة العربية من المنهج

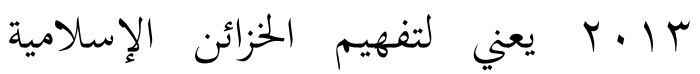
وثقفاتها العربية.

تطبيق نظرية الأسس الثقافية قد تساعد المدرّسة والتلاميذ في عملية التعليمية في مادة اللغة العربية. تطلب هذه النظرية التلاميذ للفعالة في تعليم حتي تأثر نتيجة

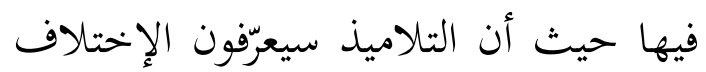
بين الأحوال والشكل البيت في العرب مع الأحوال والشكل البيت في إندونيسيا، ويشعرون بالسهولة في تعليم مادة اللغة العربية هذا يظهر بالحقائق القيمة المتوسطة

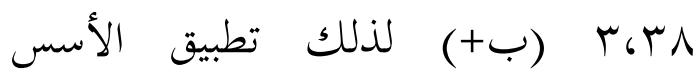
الثقافية لترقية دوافع ونتيجة التلاميذ في مادة

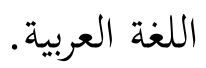

\section{Y مزايا الأسس الثقافية في تعليم} اللغة العربية بمدرسة إسماريا

\section{القرآنية}

وهناك الأسس لتعليم اللغة العربية لغير الناطقين بها منها: الأسس اللغوية، الأسس التربوية، الأسس النفسية، والأسس النس النسين

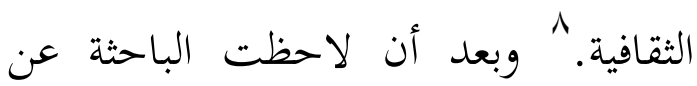
تعليم اللغة العربية بمدرسة إسماريا القرآنية، خصوصا في استخدام الأسس الثقافية تبدو

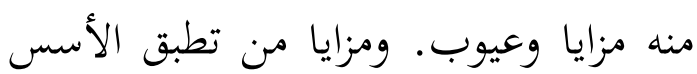
الثقافية في تعليم اللغة العربية هي: ومئه

( ) يسهل التلاميذ لفهم وحفظ

المفردات الجديدة

يدرسوفا، باستخدم الوسائل

التعليم كالصوار والفيديو في بترني

$$
\text { إعطاء المفردات الجديدة. }
$$

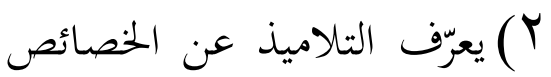

الثقافة والإجتماعية العربية

^ محمود كامل الناقة ورشدى أحمد طعيمة،

الكتاب الأساسي لتعليم اللغة العربية للناطقين بلغات

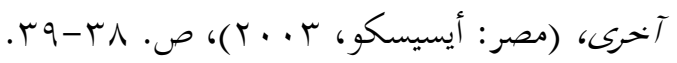

9 ملاحظة في الفصل ا السابع، في التاريخ 9

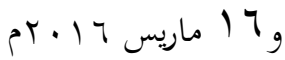


الإسلامية والأحوال البحتمع العمالة

$$
\text { العرابية. }
$$

ب) يقدّر التلاميذ ليقارن الثقافة

والإجتماعية العربية مع الثقافة

والإجتماعية الإندونيسية.

باستخدم الصوار والفيديو

المتفرقان من الثقافة وأحوال

المجتمع العرب وإندونيسيا في منركي

تنفيذ تعليمها، وتظهر

تلاميذها عن المتساويات

والإختلاف بينهما ثم تبين لهم

عن السباب التي تكون

$$
\text { الإختلاف بينهما. }
$$

؟) ترقية الرغبة والدوافع للتلاميذ

على درس اللغة العربية من

خلال التعارف على الثقافة

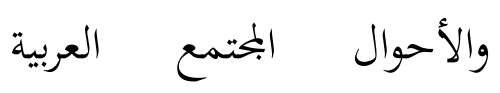

$$
\text { الإسلامية. }
$$

0) يعلّم التلاميذ عن المثل العرب

وكذلك القصة الأنبياء والتاريخ

الإسلامى. تعلّم مدرسة اللغة

العربية الأمثال العرب في تنفيذ العند
تعليم اللغة العربية. في فهاية

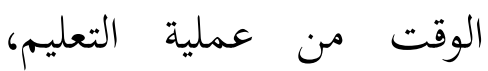

عقدت مدرّسة تلاميذها

بالقصة الأنبياء و والتاريخ

الإسلامى وهذه الوقت تقول

با "Circle time

من مزايا هذه الطريقة في تعليم اللغة

العربية وجدت الباحثة أن الأسس الثقافية جيدة باعتبار مساعدتما في ترقية الكفاءة والدوافع التلاميذ في تعليم اللغة العربية، ويستطيع التلاميذ ليتعلمون الثقافة والإجتماعية العربية الإسلامية مع تعليم اللغة العربية معا. وكذلك بهذه الطريقة يعلمون التلاميذ عن المثل العرب وكذلك

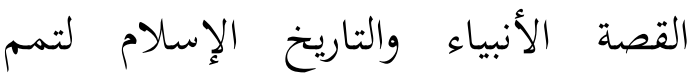
أخحلاقهم ونفوسهم.

نظرا إلى هذه الملاحظة أن التلاميذ قد فرحن في تعلّم اللغة العربية ومشاركة التفاعل عن الفهم والحفظ المفردات كاستغراق التلاميذ للمحاولة أسئلة المدرّسة 
بسرعة والرغبة في الدرس اللغة العربية بالجيد.

ومزايا من الأسس الثقافية في تعليم

اللغة العربية هي بجانب التلاميذ يفهمون المواد ونمو رغبتهم على درس اللغة العربية، هو كذلك سينالون زيادة المعرفة عن الأحوال الخزيرة العرابية السعودية وثثافتهم. أما من عيوب تطبيق الأسس الثقافية في تعليم اللغة العربية هي: '

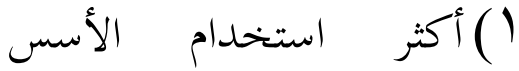
الثقافية في تعليم

$$
\text { المفردات الجمديدة. }
$$

Y) تأخذ وقتا كثيرا حينما تطبيق

الأسس الثقافية في ت تنفيذ

تعليم اللغة العربية، لأن

المدرسة تحتج الزيادة الوقت

$$
\text { للبيان الإختالاف }
$$$$
\text { الأحوال والبحتمع من ثقفتان }
$$

$$
\text { العرب وإندونيسيا. }
$$

' ملاحظة من الفصل السابع، 9 و و7 17

ماريس 7 1. Tץ.
ب) ليس لكل محتوى من مادة

في الكتاب التعليمي الأسس

$$
\text { الثقافية. }
$$

ع) أكثر التلاميذ يتركز في المعرفة

عن الثقافة العربية ليس لمادة التعليمية المدروسة.

من العيوب تطبيق الأسس الثقافية في تعليم اللغة العربية بهذه المدرسة عرفت الباحثة أن هذه الأسس أكثر التركيز، فلا بد للتلاميذ أن يتركز في مادة اللغة العربية لكى يستطيعون أن ينلوا قلاهما لمعرفة اللغوية وكذلك المعرفة الثقفية.

\section{ץ) عناصر الثقافة العربية الإسلامية} المستخدمة في عملية تعليم اللغة

$$
\text { العربية }
$$

وفقا لإدوارد ب. تايلور بتعريف الثقافة على أها تعقيد التي تشمل على العقيدة والفن والأخحاق والقانون والعادات، وتم الحصول على جميع أشكال الحياة من أفراد الجمهور. فالثقافة هي الموضوع التي يحملها المجتمع، فهي دلالة على خصائصه الأسس الثقافية في تعليم اللغة العربية 
الجموهرية وإمكاناته المادية والمعنوية، بل هو

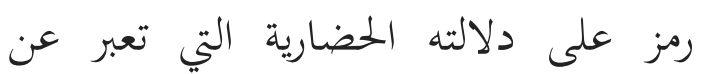
شخصيته العامة، بما تنطوي عليه من أفكار

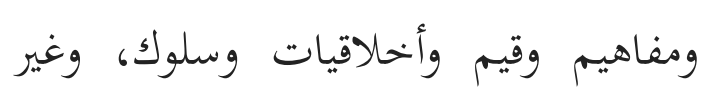
ذلك.

ينقسم إرنيس قشيرير الثقافة إلى

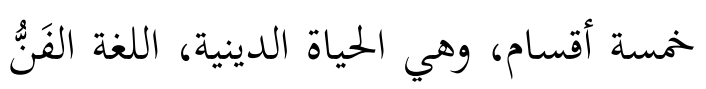

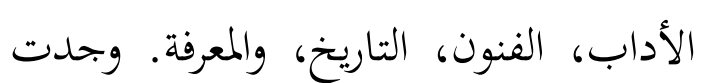
الباحثة من المقابلة مع مدرسة اللغة العلربية

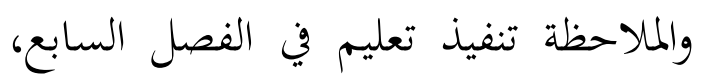
بعض العناصر الثقافة العربية الإسلامية

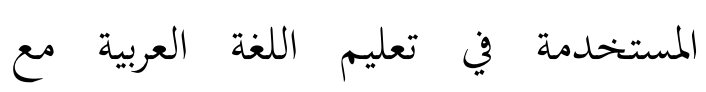
الأستاذة سوجي نوراني منها: ا ـ الأحوال البيئة العربية

Y لهجتهما في الكلام

$$
\text { بَ. الأمثال العرب }
$$

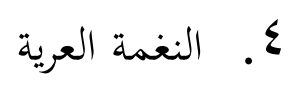

" محمد محمود الخوالدة، أساس بناء المناهج

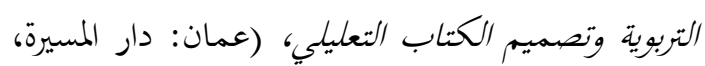

$$
.100 .06)
$$

0. القصص الأنبياء والتاريخ

الإسالامى المع

وبعد أن تلاحظ الباحثة عن تقويم

عملية تعليم مادة اللغة العربية بتطبيق

الأسس الثقافية، وجدت الباحثة أن عناصر

الثقافة المستخدمة مع مدرسة اللغة العربية بمدرسة إسماريا القرآنية المتوسطة الإسلامية بندار لامبونج مناسبة مع عناصر الثقافة من النظرية إرنيس قشيرير، منها:

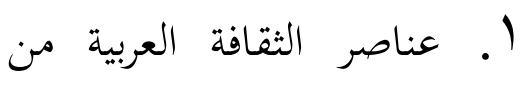

الناحية الإجتماعية

بالوسائل الصوار والفيديوا

لتظهر وتعبر تلاميذها عن

الأحوال البحتمع والبيئة

$$
\text { العربية. }
$$

ץ ب. اللغوية وهي المادة التعليمية

المدروسة من من المراجع

$$
\text { الكتاب التعلمي }
$$

"! الفنون وهي من خلال

النغامة العربية التي يسمعون

$$
\text { التلاميذ في وقت الراحة }
$$


گ. التاريخ وهي من خلال

التاريخ الت الإسلامي

تقصها المدرسة في آخر

الوقت من عملية التعليمة

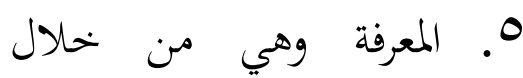

التعارف عن الثقافة العربية.

ج. أما الناحية العلم الدينية

تدخل في بحال القصص

$$
\text { الأنبياء تلخاء }
$$

وخلاصة القول أن مدرسة اللغة

العربية تستخدم جميع العناصر من العناصر الثقافية ولكن في تطبيق الأسس الثقافية

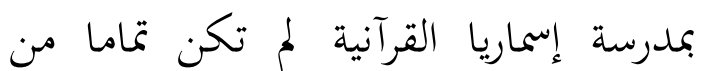
البحال عناصر الثقافة المستخدمة، كمثل الصور، فيديوا، النغامة المستخدمة أكثرها من المراجع الشبكة الدولية وبعض منها لا تكن مناسبا بالمواد المدروسة.

وهذه هي من الوظيفة لمدرسة اللغة

العربية بمدرسة إسماريا القرآنية وجميع المدارس ترس اللغة العربية لتفكير الإبتكار في البحث أي جعل أي تطور الوسائل التعليم من عناصر
الثقافة العربية الإسلامية لكي يستطيع أن تستخدمها في تنفيذ تعليم اللغة العربية ولتعرف تلاميذهم عن الثقافة العربية الإسلامية.

وقد توصل الباحثة إلى نتائج البحث التالية 1. أن مدرّسة اللغة العربية في المدرسة

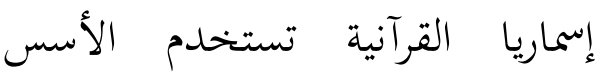
الثقافية في تعليم اللغة العربية لدي تلاميذ الصف السابع لسهولة فهمهم وترقية دوافعهم. أن الخطوة تطبيق الأسس الثقافية متساويان مع الخطوة تعليم اللغة العادية، والفرق في ادخال العناصر الثقافة العربية في تعليم اللغة العربية وتظهر المدرّسة تلاميذها عن الفروق الأحوال، والمثل، والبيئة بين العرب والإندونيسي. أن استخدام

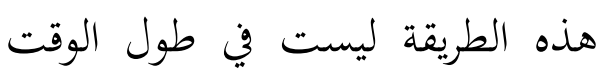

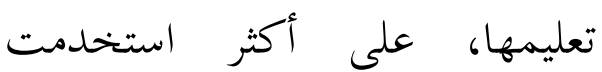
المدرّسة خطوة الأسس الثقافية في البيان عن المفردات الجحديدة. في هماية

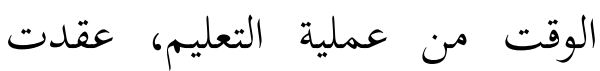


المدرّسة تلاميذها بالقصة الأنبياء

والتاريخ الإسلام وهذه الوقت تقول با بالية

"Circle time"

Y. ب مزايا الأسس الثقافية في تعليم اللغة

العربية هي يسهل التلاميذ لفهم

وحفظ المفردات الجلديدة التي

يدرسوها، يعرّف التلاميذ عن

الخصائص الثقافة والإجتماعية العربية الإسلامية والأحوال المجتمع العرابية، يقدّر التلاميذ ليقارن الثقافة

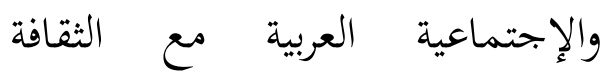
والإجتماعية الإندونيسية، ترقية الرغبة والدوافع للتلاميذ على درس اللغة العربية من خلال التعارف على الثقافة والأحوال البحتمع العربية الإسلامية، يعلّم التلاميذ عن المثل العرب وكذلك التك

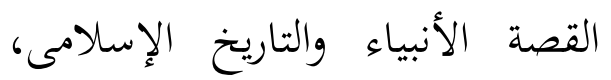
تأثر كثيرا في ترقية الكفاءة والدوافع التلاميذ في تعليم اللغة العربية. تعرف من الجدول أنّ نتيجة التعليم من القيمة المتوسطة في مدرسة إسماريا القرآنية المتوسطة الإسلامية بندار

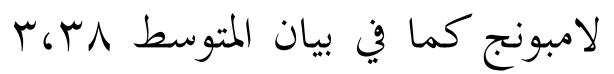

تدل أن القيمة (ب+). من هذه النتيجة فتعرف أن جودة من تطبيق الأسس الثقافية في مدرسة إسماريا القرآنية المتوسطة الإسلامية بندار لامبونج جيّدة ومطابقة لإستخدامه في تعليم مادة اللغة العربية. r. بعض العناصر الثقافة العربية الإسلامية المستخدمة في تعليم اللغة العربية مع الأستاذة سوجي نوراني كمثل المحادثة بين العربيان لاظهر لهجتهما في الكلام، وابيّن المثل أي لي لئي قول مأثور العرب التي له المعنى المتساويان مع المثل الإندونيسي،

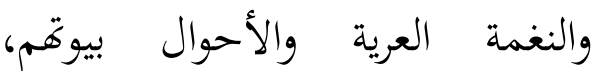
وبيئتهم، ملابيثهم، الأطعمة وشرابهم، ولهول، ولهمب، وما إلى ذلك. ويقال هذه العناصر أيضا بالوسائل التعليم من الطريقة

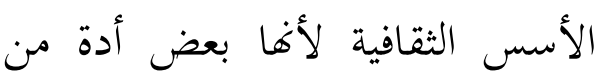

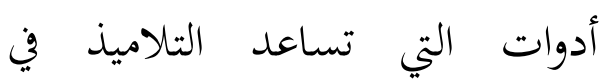
الحصول على الأهداف التعليم وهي الكفاءة الجيد في درس اللغة العربية. 


\section{يهتموها كما توجد في هذه المدرسة خلاصة}

مطابقا من نتائج هذه الدراسة

الميدانية يمكن صياغة بعض التوصيات ذات

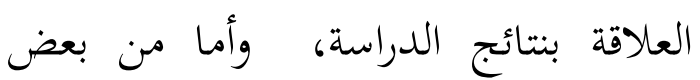

توصيات الباحثة في هذا البحث كما يلي:

ا- أن يهتم المدرّسة تطبيق الأسس

الثقافية في تعليم اللغة العربية

اهتماما جيدا وبالإضافة إلى إملاء

النقصان من الوسائل التعليم

$$
\text { المستخدمة (الصوار والفيديو). }
$$

r-أن يحاول التلاميذ الحفظ المفردات

كثيرا ويفهمون السؤال والأمر من

التدريبة لكي يستطيعون أن يجب ويعول

$$
\text { السؤال صحيحا. }
$$

ب--يمكن للجامعة مولان مالك إبراهيم

أن ترعي إلى بحوث عن النظرية

تعليم اللغة الثانية عامة واللغة العربية

$$
\text { خاصة. - ماصن }
$$

ك- ينبغي لكل المعلمين اللغة العربية

التفكير الإبتكار والمفصل في تعليم

اللغة العربية، ولذلك لا بد لهم أن

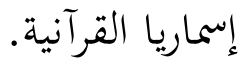

○- إن نتائج هذا البحث العلمي يمكن

أن يفيد مدرسة في تنمية وترقية

إبحاح العملية التعليم في مادة اللغة

العربية وترقية التحصيل الدراسي

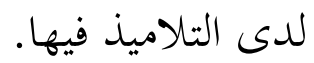

\section{مراجع الكتابة}

زكريا، إسماعيل. طرق تلدريس اللغة العربية.

دار المعرفة الجامعية، 1990.

حضيري، ميلاد محمد المبروك ومحمد فرج

أبوتبينة. كفايات معلم اللغة العربية

للناطقين بغيرها وفق معايير الجودة

والإتقان في سجل المؤتمر الدولي

الثاني. مالانج: Aditya Media

$. Y \cdot I \leqslant$ (Publishing

الخوالدة، محمد محمود. أساس بناء المناهج

التربوية وتصميم الكتاب التعليلي.

عمان: دار المسيرة، Iل ب. ب.

الناقة، محمود كامل ورشدى أحمد

طعيمة. الكتاب الأساسي لتعليم 
اللغة العربية للناطقين بلغات

آخرى أعلداده، تحليله، تتويمه.

مكة المكرمة: جامعة أم القرى،

\section{.1994}

طعيمة، رشدي أحمد. أساس المعجمية

والثقافية لتعليم اللغة العربية لغير

الناطقين بها. مكة الملكرمة:

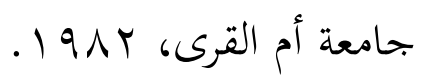

الناقة، محمود كامل ورشدى أحمد

طعيمة. الكتاب الأساسي لتعليم

اللغة العربية للناطقين بلغات

آخرى. مصر: أيسيسكو،

$r \cdot r$ 